\title{
Vibration control of Multi Degree of Freedom structure under earthquake excitation with TMD control and active control force using fuzzy logic method at the highest and the lowest story of the building
}

\author{
M. Ali Lotfollahi Yaghin ${ }^{1}$, M. Reza Bagerzadeh Karimi², B. Bagheri ${ }^{3}$, \\ V. Sadeghi Balkanlou ${ }^{4}$ \\ ${ }^{I}$ Prof. of Faculty of Civil Engineering, University of Tabriz, IRAN \\ ${ }^{2}$ Department of Civil Engineering, Islamic Azad University, Maraghe Branch, IRAN \\ ${ }^{3}$ Department of Civil Engineering, Shomal University, IRAN \\ ${ }^{4}$ Young Researchers and Elite Club, Islamic Azad University, Tabriz branch, IRAN
}

\begin{abstract}
In this paper, Control system performance, as a passive and active control on the example building under the Bam earthquake excitation, was studied. In order to passive and active control the structure TMD system mounted on the top floor of the building and FLC method was used, respectively. Active control system first applied to the lowest floor then to the highest point of the structure (applied to the TMD system). Mathematical model of the building is established in MATLAB. Equation of motion was written for high rise building and it was solved by state-space method, the Results are illustrated and compared.
\end{abstract}

Keywords : MATLAB; Active and Passive control; Fuzzy Logic Controller; Tuned Mass Damper

\section{INTRODUCTION}

The developments in engineering science in vibration control of structures, and security needs for occupants to feel safe against earthquake cause researchers to study more in the field of vibration control of structures. Vibration control systems can be divided into Passive and Active control systems. Passive control systems add damping to the structure, naturally, when an earthquake occurres. However, their control capacity is limited. But these systems have been widely used because of their simplicity and low cost. The active control systems use external energy when an earthquake happens. This energy produced by algorithm and applied to the structure has the advantage of having stronger capacity than Passive control systems. Also it can be designed to influence a number of vibration modes, and it is the most suited for an MDOF structure. On the other hand, passive control systems and active control systems are used together in order to decrease the energy requirements. Researches show that increasing the height of buildings could increase the flexibility; thus, the importance of the active control systems has increased [1]. Rahmi and et al. [1] studied about vibration control of structures using fuzzy logic and PD controller and an actuator was applied at the highest point of the structure where the TMD had been located. Seung-Yong and et al. [2] investigated about vibration control of structure using a technique with fuzzy logic method. Mahmud and et al. [3] examined an optimized control for an earthquake excitation on a structure. Hasan and et al. [4] studied about FSMC which is one of the active control algorithms. Pourzeynal and et al. [5] studied about vibration control of structure against earthquake excitation using GFLC and LQR algorithms and compared with TMD controller. Bijan and et al. [6] used experimental analysis and investigated a five-story building where ATMD system was controlled by FLC and LQR method. As it is clear by researches only the effects of control systems are studied and investigated on civil engineering structures, but the effects of the opportunities and the location of control systems, namely applying at the highest and the lowest point of the structure in order to reach optimized responses, are not investigated. The present paper studied and investigated a 10-story building using active control system which was first applied to the TMD system then to the lowest floor of the building. Also the results were compared with the responses of the TMD control system in order to show robustness of FLC in example building.

II. STRUCTURAL MODEL

The equation of motion for a multi-degree-of-freedom structure subjected to seismic excitation $\ddot{x}_{g}(t)$ without any control system can be written as:

$[M]\{\ddot{x}\}+[C]\{\dot{x}\}+[K]\{x\}=-[M]\{r\} \ddot{x}_{g}(t)$ 
In which the $n \times 1$ vector $\{x\}$ the relative displacement of each story; $n$ is the number of stories; the $n \times 1$ vector $\{r\}$ is the influence vector representing the displacement of each degree of freedom resulting from static application of a unit ground displacement; and $\mathrm{n} \times \mathrm{n}$ matrices $[\mathrm{M}],[\mathrm{C}]$ and $[\mathrm{k}]$ represent the structure mass, damping, and stiffness matrices, respectively. The structural damping matrix $[\mathrm{C}]$ is assumed to be a proportion of the mass and stiffness matrices, as given in the following [5]:

$[C]=a_{0}[M]+b_{0}[K]$

Where $\mathrm{a}_{0}=\xi_{\mathrm{i}} \times \frac{2 \omega_{\mathrm{\imath}} \times \omega_{\mathrm{j}}}{\omega_{\mathrm{l}}+\omega_{\mathrm{j}}}$ and $\mathrm{b}_{0}=\xi_{\mathrm{i}} \times \frac{2}{\omega_{\mathrm{l}}+\omega_{\mathrm{j}}}, \mathrm{a}_{0}$ and $\mathrm{b}_{0}$ are the proportional coefficient; $\omega_{\mathrm{t}}$ and $\omega_{\mathrm{j}}$ are the structural modal frequencies and $\xi_{\mathrm{i}}$ and $\xi_{\mathrm{j}}$ are the structural damping ratio for modes $\mathrm{i}$ and $\mathrm{j}$, respectively. This paper also studied the effects of TMD, a classical engineering device consisting of a mass, a spring and a damper, on multi-degree- of-freedom structure. For this purpose, as shown in Fig. 1, a TMD system is mounted on the top floor of the building. The equation of motion of multi-degree-of-freedom linear system which is subjected to a seismic excitation $\ddot{x}_{\mathrm{g}}(\mathrm{t})$ and active control action $\{\mathrm{f}\}$ can be written as:

$$
\left[\mathrm{M}_{\mathrm{T}}\right]\left\{\ddot{\mathrm{x}}_{\mathrm{T}}\right\}+\left[\mathrm{C}_{\mathrm{T}}\right]\left\{\dot{\mathrm{x}}_{\mathrm{T}}\right\}+\left[\mathrm{K}_{\mathrm{T}}\right]\left\{\mathrm{x}_{\mathrm{T}}\right\}=-\left[\mathrm{M}_{\mathrm{T}}\right]\left\{\mathrm{r}_{\mathrm{T}}\right\} \ddot{\mathrm{x}}_{\mathrm{g}}(\mathrm{t})+[\mathrm{D}]\{\mathrm{f}\}
$$

In which the $n \times 1$ vector $\left\{\mathrm{x}_{\mathrm{T}}\right\}$ designates the relative displacements of each story. Square matrices $\left[\mathrm{M}_{\mathrm{T}}\right],\left[\mathrm{C}_{\mathrm{T}}\right]$, $\left[\mathrm{K}_{\mathrm{T}}\right]$ and $\left\{\mathrm{r}_{\mathrm{T}}\right\}$ are the same explained in Eq. 1, and $\mathrm{n} \times 1$ vector $\{\mathrm{f}\}$ contains the externally applied control forces whose locations are identified through the matrix [D].

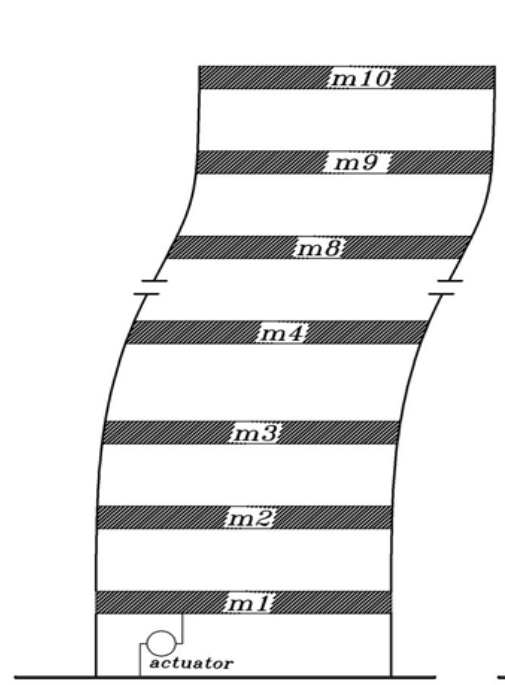

(a)

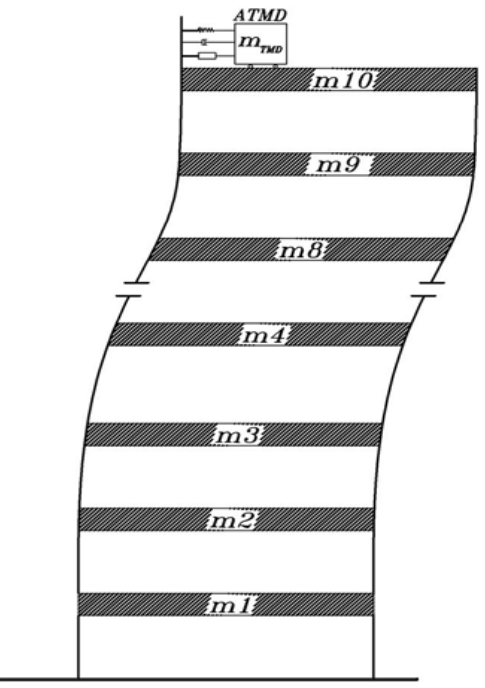

(b)

Fig. 1 Example building of using active control system: a) applied to the first floor b) applied to the TMD system

\section{FUZZY LOGIC}

Fuzzy set was introduced by Lotfi Zadeh in 1965. Fuzzy set deals with uncertain phenomena often presented in real-life application. What makes fuzzy logic and classical mathematics different is that the fuzzy set theory allows object to have any degrees of membership between zero and 1 but the classical mathematics requires objects to have zero or 1 [12].

The basic structure of fuzzy system which works with Fuzzy Logic is defined as follows:

Fuzzifier: inputs measured in the control process and converted into fuzzy linguistic value using the rules as given in table 1 . In order to limit the amplitude of variables between 1 and -1 , they are divided into their maximums.

Fuzzy rules: this is the collection of the expert control rules (table 1). These rules are used to connect outputs and inputs in fuzzy logic system.

Fuzzy interference engine: after converting the inputs to linguistic variables, the outputs are defined by fuzzy logic rules.

Defuzzifier: then the defuzzifier converts the outputs of fuzzy logic system to crisp data [13]. The basic structure of fuzzy logic algorithm is illustrated in Fig. 2. 


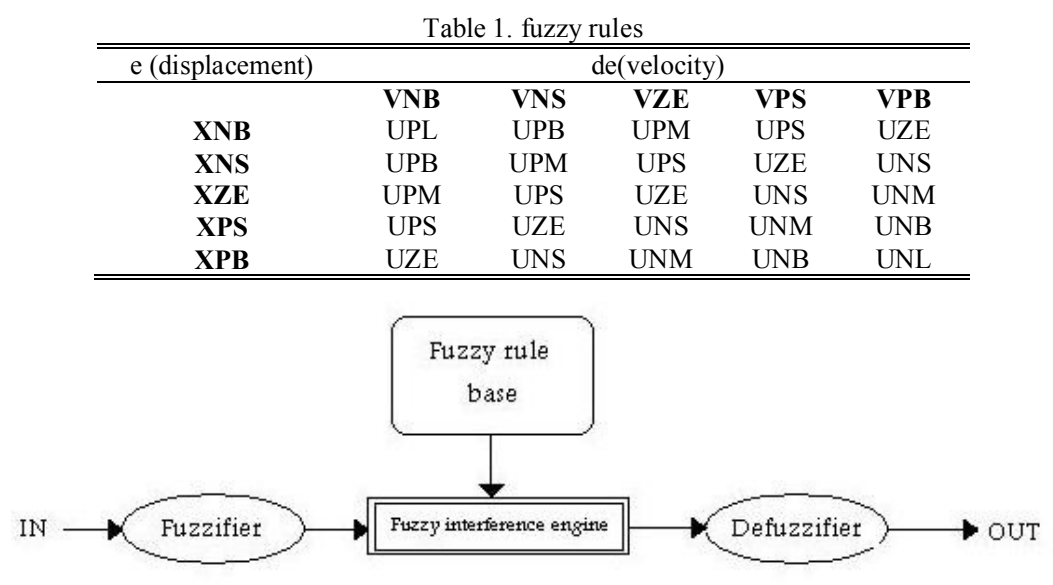

Fig. 2 fuzzy logic components

\section{NUMERICAL STUDY}

In order to investigate the effects of active control system and TMD to decrease the responses under the earthquake excitation of BAM earthquake, happened in 2003 in IRAN (Fig. 3), a 10-story building was modeled in MATLAB (Fig. 1). The structure's properties of example building are provided in Table 2.

Table 2

Example building structure data

\begin{tabular}{crc}
\hline \hline Stories & Mass $(\mathrm{kg})$ & Stiffness $(\mathrm{kg} / \mathrm{m})$ \\
\hline 1 & 42180 & 114938011 \\
2 & 42180 & 114938011 \\
3 & 41791 & 87486851 \\
4 & 41791 & 87486851 \\
5 & 41430 & 65258739 \\
6 & 41430 & 65258739 \\
7 & 41097 & 47547051 \\
8 & 41097 & 47547051 \\
9 & 40791 & 33696384 \\
10 & 40791 & 33696384 \\
TMD & 4146 & 177333 \\
\hline \hline
\end{tabular}

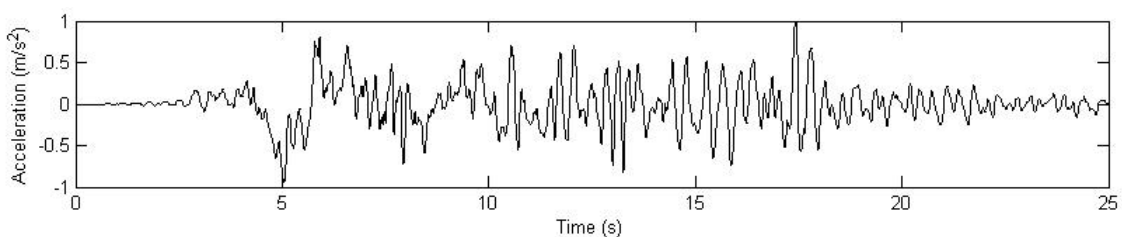

Fig. 3 Bam earthquake excitation input to the structure

To passive control the vibration TMD system is mounted on the top floor of the building and for active controlling the structure it was applied to the first floor then to the highest point of the structure where the TMD system mounted. In order to reach maximum decrease of vibration of using TMD system, the mass of the TMD obtained by trial and error about $1 \%$ of the whole building's mass. To find the stiffness of the passive control system the natural frequency of TMD is tuned to the main natural frequency of the main structure, as follows:

$\omega_{i}^{2} \times m_{T M D}=k_{T M D}$

In which $\mathrm{m}_{\mathrm{TMD}}$ and $\mathrm{k}_{\mathrm{TMD}}$ and $\omega_{\mathrm{t}}$ are the mass, stiffness, and the main frequency of the first mode, respectively. The most optimized parameter of this system is defined by maximum decrease of responses of the building. Also the same parameters of the mass were used for active control system when active control force applied to the TMD system. In this study, Matlab simulink with fuzzy toolbox is used. The aim of the fuzzy logic control system for the structural system uses e and de as inputs and $u$ as an output where the active control system is applied. For each of inputs, five rectangular membership functions are used which cover the amplitude of each input. Also, nine rectangular membership functions are used for outputs (Fig. 4). Fuzzy logic controller with Mamdani and Centroid methods were used in fuzzification and defuzzification, respectively. Scaling factors (se, 
sde, su) are used to set in Fig. 5. The fuzzy input and output variables' membership function abbreviations used to define the fuzzy space are: $(\mathrm{X} / \mathrm{V}) \mathrm{NB}=$ negative big; $(\mathrm{X} / \mathrm{V}) \mathrm{NS}=$ negative small; $(\mathrm{X} / \mathrm{V}) \mathrm{ZE}=$ zero; $(\mathrm{X} / \mathrm{V}) \mathrm{PB}=$ positive big; (X/V)PS = positive small (for input variable); and (U)NL = negative large; (U)NB = negative big; $(\mathrm{U}) \mathrm{NM}$ = negative medium; (U)NS = negative small; (U)ZE = zero; (U)PL = positive large; (U)PB = positive big; (U)PM = positive medium; (U)PS = positive small (for output variable).
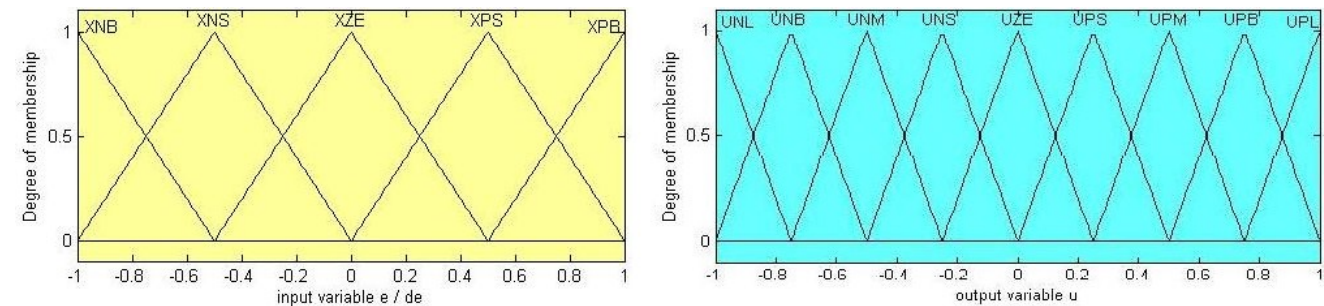

Fig. 4 Membership function

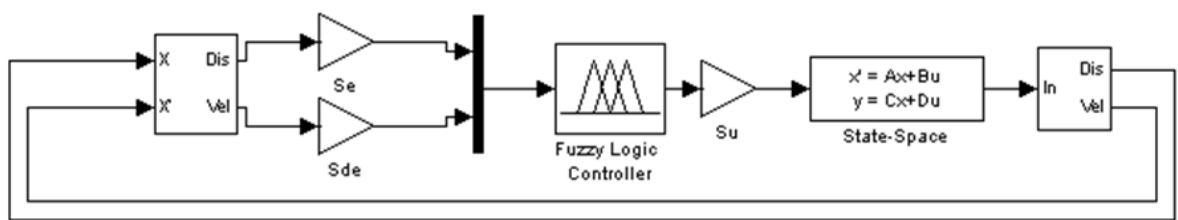

Fig. 5 Closed-loop model of the structure with fuzzy logic controller

Table 3

Comparison between the effects of control system on structure under Bam Earthquake

\begin{tabular}{|c|c|c|c|c|c|c|c|}
\hline \multirow[b]{2}{*}{ stories } & \multirow{2}{*}{$\begin{array}{c}\text { Max. responses } \\
\text { of uncontrolled structure }\end{array}$} & \multicolumn{3}{|c|}{$\begin{array}{c}\text { Max. responses } \\
\text { of controlled structure }\end{array}$} & \multicolumn{3}{|c|}{ Ratios } \\
\hline & & $\begin{array}{c}\text { Passive } \\
\text { control system } \\
\text { with TMD }\end{array}$ & $\begin{array}{l}\text { Active control } \\
\text { system applied to } \\
\text { the first floor }\end{array}$ & $\begin{array}{l}\text { Active control } \\
\text { system applied } \\
\text { to TMD }\end{array}$ & {$[2] /[1]$} & {$[3] /[1]$} & {$[4] /[1]$} \\
\hline & [1] & [2] & [3] & [4] & [5] & [6] & [7] \\
\hline \multicolumn{8}{|c|}{ Displacement (m) } \\
\hline $10^{\text {th }}$ & 0.036 & 0.031 & 0.01 & 0.003 & 0.861 & 0.278 & 0.084 \\
\hline \multicolumn{8}{|c|}{ Velocity $(\mathbf{m} / \mathbf{s})$} \\
\hline $10^{\text {th }}$ & 0.247 & 0.187 & 0.073 & 0.0366 & 0.757 & 0.296 & 0.148 \\
\hline \multicolumn{8}{|c|}{ Acceleration $\left(\mathrm{m} / \mathrm{s}^{\wedge} 2\right)$} \\
\hline $10^{\text {th }}$ & 2.505 & 2.221 & 0.833 & 0.643 & 0.887 & 0.333 & 0.256 \\
\hline
\end{tabular}

As it is clear from table 3, responses of the structure for the top floor of the building (10th floor) show the proportion of controlled structure, the results are $86.1 \%, 27.8 \%, 8.4 \%$ for displacement, $75.7 \%, 29.6 \%, 14.8 \%$ for velocity and $88.7 \%, 33.3 \%, 25.6 \%$ for acceleration controlled by TMD and FLC systems where the active control system applied to the first floor and to the TMD system, respectively. Figures 6 - 8 show the responses (displacement and acceleration) for the uncontrolled and the controlled structure. As it can be seen from figures 6-8 the amplitude of vibration has decreased. Also, to clarify the results, displacements of floors are illustrated in fig.9.
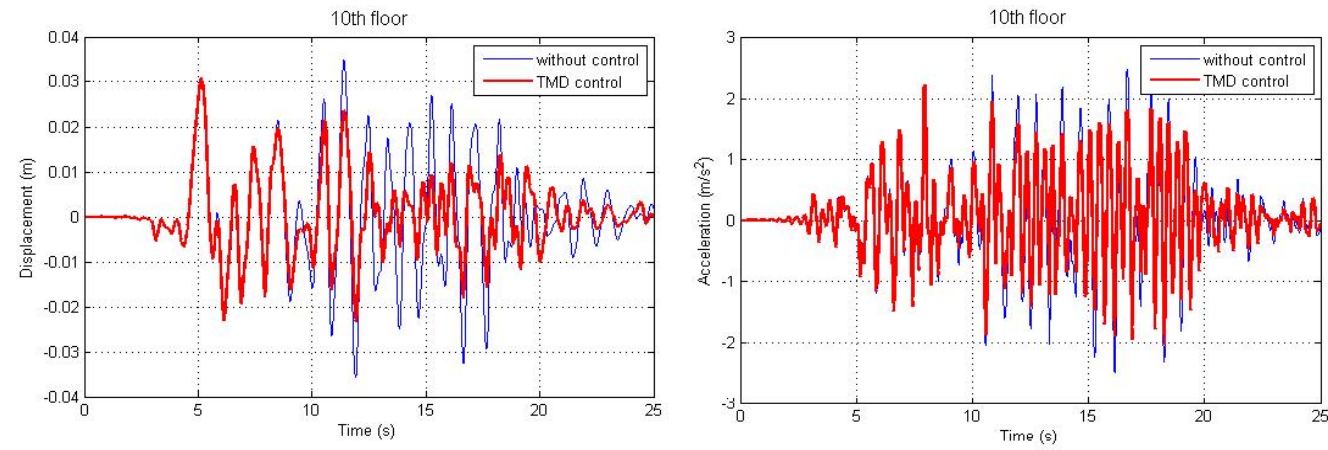

Fig. 6 passive control of displacement and acceleration for the 10th floor using TMD 

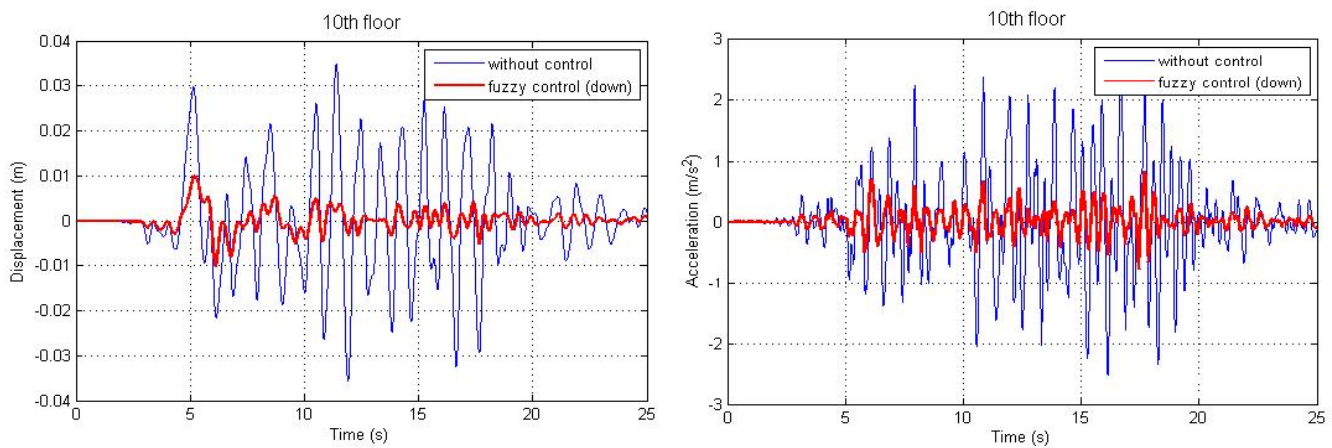

Fig. 7 Active control of displacement and acceleration for the 10th floor with FLC method when control force applied at the lowest floor of the building
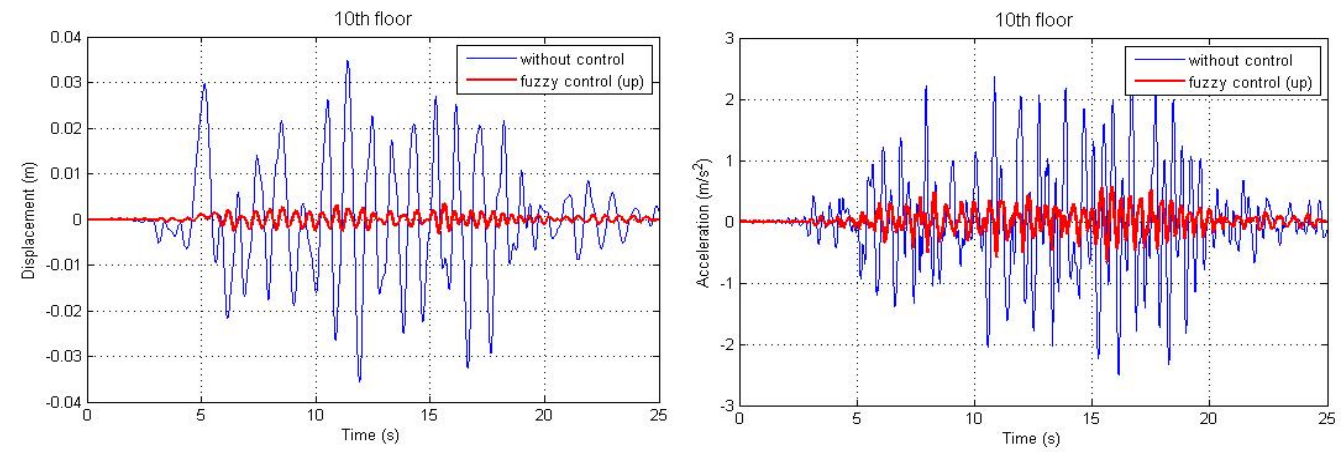

Fig. 8 Active control of displacement and acceleration for the 10th floor with FLC method when control force applied to the TMD system

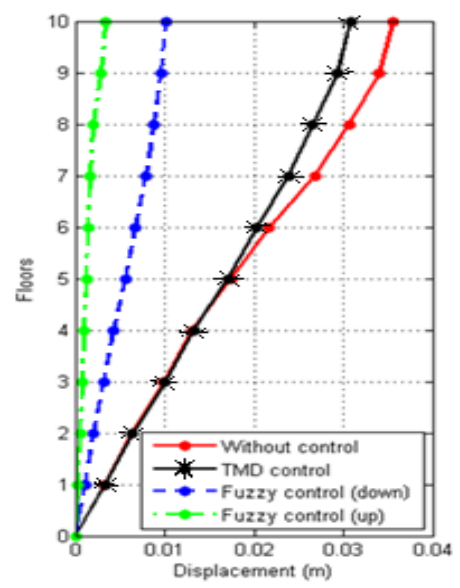

Fig. 9 Displacements

On the other hand, the fuzzy logic application is investigated against different disturbance using ground motion of TABAS earthquake, happened in 1999 in IRAN, the acceleration was about $0.84 \mathrm{~g}$, also the mass of each floor increased about $25 \%$. Robustness of FLC has been investigated through this variety of buildings' parameters. The results in Table 4 show the robustness of FLC even for different parameters of inputs in example building.

Table 4

Comparison between the effects of control system on structure under Tabas earthquake for displacement

\begin{tabular}{|c|c|c|c|c|}
\hline \multirow{2}{*}{ stories } & \multirow{2}{*}{$\begin{array}{l}\text { Maximum responses } \\
\text { of uncontrolled structure }\end{array}$} & \multicolumn{3}{|c|}{ Maximum responses of controlled structure } \\
\hline & & $\begin{array}{c}\text { TMD } \\
\text { Displacement (m) }\end{array}$ & FLC (down) & FLC (up) \\
\hline 10 & 0.313 & 0.301 & 0.085 & 0.034 \\
\hline
\end{tabular}




\section{CONCLUSION}

In the present study when the active control force applied on certain parts of the building from the numerical results of the study, it is found that:

1) In view of the time history of the responses, the results show that when the active control force is applied to two certain parts of the example building are more satisfactory compared when the passive control system (TMD) is only used.

2) In this study as it is clear by table 3, the most satisfactory control case was found when active control system applied to the TMD system.

3) Performance of designed FLC is checked for different disturbance using ground motion of TABAS, and also changed some properties of structure. Simulation's results show that proposed controller (FLC) has a satisfactory performance and does not get worse. Decrease in vibration amplitudes supports this result (Table 4).

\section{REFERENCE}

[1] Rahim Guclu, Hakan Yazici "Vibration control of a structure with ATMD against earthquake using fuzzy logic controllers"; journal of sound and vibration 2008, 318: 36-49.

[2] Kwan-Soon Park, Hyun-Moon Koh, Seung-Yong Ok "Active control of earthquake excited structures using fuzzy supervisory technique"; Advance in Engineering Software 2002, 33:761-768.

[3] M. S. Mahmud, M. Zribi, Y. C. Soh, "Optimal control of seismically-excited building structures", Computers and structures, 2000, 74: $521-533$

[4] Hasan Alli, O־guz Yakut, "Fuzzy sliding-mode control of structures", Engineering Structures, 2005, 27: 277-284

[5] S.Pourzeynali, H.H. Lavasani, A.H.Modarayi "Active control of high rise building structures using fuzzy logic and genetic lgorithms"; Engineering Structure 2007; 29 : 346-357.

[6] Bijan Samali, Mohammad Al-Dawod " Performance of a five-storey bench mark ,odel using an active tuned mass damper and fuzzy logic"; Eng. Structure 2003, $25: 1597-1610$.

[7] Clough RW, Penzien J. Dynamics of structures. 2nd. New York: McGraw-Hill; 1993.

[8] N. Yagiz, R. Guclu, I. Yuksek "Aktif kutlu sonumleyicili cok serbestlik dereceli bir yapinin depreme karsi LQR kontrolu", muhendis ve makine, say1: 2001, 498: 20-24 (In Turkish)

[9] Zhi Q. Gu, S. Olutunde Oyadiji "Application of MR damper in structural control using ANFIS method",Computers and structures, 2008, 86: 427-436

[10] A. Kumar, Poonam, B. Saini, V.K. Sehgal "Active vibration control of structures against earthquakes using modern control theory", civil engineering, 2007, vol 8: 283-299

[11] Mohammed Aldawod, Bijan Samali, Fazel Naghdy, Kenny C.S. Kwok "Active control of along wind response of tall building using a fuzzy controller", Engineering Structures, 2001, 23: 1512-1522

[12] L. A. Zadeh, "Fuzzy Sets", information and control 1965, 8: 338-353

[13] J.S.Roger Jang, Ned Gulley, "MATLAB Fuzzy Logic Toolbox", printing history: April 1997

[14] Hakan Yazici, Rahmi Guclu"Self-tuning tuning fuzzy logic controller of vibrations Multi-Degree-of-Freedom structural system"

[15] A. Rajagopalan, G. Washington, G. Rizzoni, and Y. Guezennec "Development of Fuzzy Logic and Neural Network Control and Advanced Emissions Modeling for Parallel Hybrid Vehicles"

[16] Detlef Nauk, Rudolf Kruse "a fuzzy neural network learning fuzzy control rules and membership function by fuzzy error back propagation"

[17] R. Alcal', J. Casillas, A. Gonz'alez "Tuning Fuzzy Logic Controllers for Energy Efficiency Consumption in Buildings"Jan Jantzen, "Design Of Fuzzy Controllers" 